\title{
Breaking Engagement Apart: The Role of Intrinsic and Extrinsic Motivation in Engagement Strategies
}

\author{
Molly L. Delaney and Mark A. Royal \\ Korn Ferry Hay Group
}

\begin{abstract}
Employee engagement has long been an instrumental component of human capital strategies and continues to dominate the conversation about how high-performing organizations attract and retain their best talent. Engagement is a construct of component parts, however, and we believe there is still much to be learned about engagement by taking an in-depth look at those components. This article examines employee motivation as a core element of engagement, including its antecedents and outcomes, the types of motivation and the dynamics between them, and the ways organizations can foster and harness motivation for improved engagement. Our research identifies a large and consistent motivation gap, such that employee intrinsic motivation is consistently higher than extrinsic motivation. This gap signals that investments in engagement can yield a higher return if strategically focused on motivation, and so we offer recommendations regarding how to close this gap via intrinsically and extrinsically motivating work structures and environments. The goal is to create a new dialogue around engagement and encourage organizations to break it down in order to understand it more fully.
\end{abstract}

Employee engagement has long been an instrumental component of human capital strategies and continues to dominate the conversation about how high-performing organizations attract and retain their best talent. There are good reasons for the organizational focus on engagement. In rapidly changing business environments, roles and responsibilities are often hard to specify, and organizations must count on employees to act independently in ways consistent with organizational objectives, culture, and values. The extra effort given by these individuals is a vital asset in our knowledge-based economy, particularly for organizations needing to do more with less. Also, there's no shortage of research to support the business case for engagement. Proponents report positive relationships between engagement and business

Molly L. Delaney and Mark A. Royal, Korn Ferry Hay Group, Chicago, Illinois.

Correspondence concerning this article should be addressed to Molly L. Delaney, who is now at Google, Inc., 1600 Ampitheater Way, Mountain View, CA 94043. E-mail: mollyldelaney@google.com 
success at all levels of the organization, from financial performance and customer satisfaction (e.g., Harter, Schmidt, \& Hayes, 2002) to team productivity and innovation (e.g., Griffin, Parker, \& Neal, 2008) and, finally, to employee performance and retention (e.g., Lockwood, 2007).

Engagement is a construct of component parts. Many consulting organizations offer their own perspectives regarding how it is defined and measured, but all report it in its final, composite form. Despite all that we know about engagement, we believe there is still much to be learned by taking an in-depth look at the component parts and understanding them more fully. We need to break engagement apart in order to enhance it more quickly.

Although measures of organizational commitment are also commonly included, at the core of any conceptualization of engagement is employee motivation. It drives behavior and orients energy based on anticipated outcomes, particularly those that promise the greatest return on investment (Vroom, 1964). Where this motivation comes from, however, and how it drives behavior, can lead to different outcomes. In this article, we take a closer look at employee motivation, including its antecedents and outcomes, the types of motivation and the dynamics between them, and the ways organizations can foster and harness motivation for improved engagement.

\section{Motivation Is a Key Component of Engagement and Performance}

The most fundamental consideration for human capital strategies is whether or not employees are positioned to act in ways that advance the organization toward its goals. Engagement is a primary means of aligning employee efforts, along with known drivers of engagement, such as knowledge management, change management, and capability building.

According to our research, motivation is a key component of engagement. Of the five components of our engagement index, we found that the extent to which employees themselves feel motivated to do more than is required is the top predictor of overall engagement, followed by the extent to which the company motivates employees to do more than is required of them. This means that investments in motivation maximize utility by yielding the highest return on overall engagement.

Those investments also help direct employee efforts toward key priorities. By structuring activities related to priorities in interesting and compelling ways, and by incenting those activities in ways that resonate with needs and values, organizations can ensure that employees stay focused on what moves strategy forward. This involves some prework, as organizations need to know what employee skills and abilities are available, how to leverage those skills and abilities effectively, and which incentives will be most valuable. The result, however, is improved alignment and faster progress toward strategic goals. 
Motivation helps employees to be proactive in moving strategies forward, but it also helps them to react more quickly when obstacles stand in the way. Building a reserve of motivation and, by extension, discretionary effort, is important for adapting to new conditions and navigating unforeseen circumstances. During times of change, when motivation is often depleted due to conflicting priorities, the ability to draw on those reserves can increase resilience and ensure that people stay focused on what matters most. Indeed, the extent to which employees are already motivated has been shown to improve attitudes toward organizational change (Choi, 2011).

Finally, and perhaps most importantly, when employees are motivated, they invest additional time and energy into their jobs, identify new ways to be efficient, and commit more thought and creativity to their projects-and all of this leads to better performance. But how long this motivation can be sustained, and whether it has short-term or long-term implications, depends on its source.

\section{Intrinsic and Extrinsic Motivation}

Not all motivation is created equal. Broadly, there are two types of motivation: that which is internally derived, or intrinsic, and that which is externally derived, or extrinsic (Deci, 1971; Ryan \& Deci, 2000). It is important to understand the differences and dynamics between them, as they drive behavior via separate pathways and result in different outcomes.

Intrinsic motivation is internal to the individual and inspired by experiences that connect with self-concept and personal drives. As a result, these experiences are inherently interesting or enjoyable, such that employees work for the excitement, accomplishment, and personal satisfaction they feel both in the process of carrying out activities and in the results (Deci \& Ryan, 1985). Intrinsic motivation is most likely to occur when activities align with personal attitudes, orientations, or values, or when the work is personally meaningful in some way.

Previous research has established that intrinsic motivation enhances both performance and productivity (e.g., Grant, 2008). According to our global employee opinion normative benchmarks, ${ }^{1}$ we find that $76 \%$ of employees who exceed performance expectations feel motivated to do more than is required of them, compared with $67 \%$ of employees who meet performance expectations and $57 \%$ of employees who do not, which suggests that intrinsic motivation is associated with better performance. Intrinsic motivation also builds additional energy. When employees invest in work

${ }^{1}$ Korn Ferry Hay Group's global normative benchmarks are based on data collected from over 6.4 million employees in 390 organizations around the world in a variety of industries. 
because it is personally interesting or enjoyable, they commit to it fully without depleting internal resources (Ryan \& Deci, 2008). Additionally, employees who are intrinsically motivated are more creative, solve problems more efficiently and effectively, and demonstrate better conceptual thinking (Deci, 1995).

By contrast, extrinsic motivation is external to the individual and influenced by the organization and work environment. Behavior is driven by the influence of outside sources such as social norms, peer influence, authority, or promises of reward, and it is focused on the utility of the activity rather than the activity itself (Deci \& Ryan, 1985).

This is not to say that, as a behavioral driver, extrinsic motivation is less effective or important (Deci, Koestner, \& Ryan, 1999). Rewards and incentives, two commonly referenced extrinsic motivators, are critical for directing efforts toward the right organizational goals and providing employees with the inducements needed to perform at high levels (Kinnie, Hutchinson, Purcell, \& Swart, 2006). Many consider financial incentives to exert the most potent influence on employee performance (e.g., Baker, Jensen, \& Murphy, 1988; Gerhart \& Rynes, 2003; Jenkins, Mitra, Gupta, \& Shaw, 1998; Locke, Shaw, Saari, \& Latham, 1981; Skaggs, Dickinson, \& O'Connor, 1992). In a meta-analysis of productivity-enhancing interventions, Locke and colleagues found that the introduction of pay incentives increased productivity by an average of 30\% (Locke, Feren, McCaleb, Shaw, \& Denny, 1980). For extrinsic motivators to work, however, there must be clarity about behavioral expectations and resulting outcomes. In accordance with expectancy theories, for example, if employees are to be extrinsically motivated by financial incentives, they must understand the criteria on which they are evaluated, what success looks like based on those criteria, and whether there is alignment between the volume of work it takes to be successful and the payouts they expect to receive as a result.

Our normative benchmarks also suggest that extrinsic motivation is associated with improved performance. More specifically, we find that $60 \%$ of employees who exceed performance expectations are motivated by their organizations, compared with $55 \%$ of those who meet expectations and $48 \%$ of those who do not. Although these numbers are compelling, the performance distinctions are not as sharp as with varying levels of intrinsic motivation, suggesting that intrinsic motivation might be the better performance differentiator.

In absolute terms, when we isolate those who exceed performance expectations, we find that a significantly higher proportion endorse feeling intrinsically motivated (76\%) than extrinsically motivated (60\%). Then, in relative terms, when we compare those who meet expectations with those who exceed them, we find a larger difference in those who endorse feeling 
Table 1. The Connection Between Intrinsic Motivation, Extrinsic Motivation, and Employee Performance

\begin{tabular}{lcc}
\hline \hline & $\begin{array}{l}\text { "I feel motivated to do more } \\
\text { than is required of me." } \\
\text { (intrinsic motivation) }\end{array}$ & $\begin{array}{l}\text { "The company motivates me } \\
\text { to do more than is required." } \\
\text { (extrinsic motivation) }\end{array}$ \\
\hline $\begin{array}{c}\text { Exceeds performance } \\
\text { expectations } \\
\begin{array}{c}\text { Meets performance } \\
\text { expectations }\end{array}\end{array}$ & $76 \%$ & $60 \%$ \\
$\begin{array}{l}\text { Does not meet } \\
\text { performance } \\
\text { expectations }\end{array}$ & $67 \%$ & $55 \%$ \\
\hline \hline
\end{tabular}

intrinsically motivated ( $+9 \%$, from $67 \%$ to $76 \%$ ) than extrinsically motivated $(+5 \%$, from $55 \%$ to $60 \%$; see Table 1$)$.

The notion that high performance is more strongly associated with intrinsic motivation is supported in a variety of research contexts. For example, Amabile and colleagues found that extrinsic motivators, such as salaries and public recognition, were not primary drivers of employee behavior (Amabile, Hill, Hennessey, \& Tighe, 1994). Instead, intrinsic motivation was found to be the better driver of persistence, performance, and satisfaction, in a variety of tasks and in various domains, compared with extrinsic motivation (Baard, Deci, \& Ryan, 2004; Black \& Deci, 2000; Deci, Connell, \& Ryan, 1989; Williams, Grow, Freedman, Ryan, \& Deci, 1996).

Although they drive behavior via separate mechanisms, intrinsic and extrinsic motivation do influence one another. For example, Yoo and colleagues found that, when extrinsic goals are self-endorsed, or when extrinsic motivators (e.g., rewards, communication, feedback) satisfy internal needs (e.g., feelings of competence or satisfaction), they are adopted with a greater sense of volition. In this way, extrinsic motivation is converted to intrinsic motivation, which in turn has a powerful influence on behavioral intentions (Yoo, Han, \& Huang, 2012).

At the same time, overemphasis on extrinsic motivation, particularly if it is reward focused, can undermine intrinsic motivation. Although hotly debated, meta-analytic techniques provide strong evidence to suggest that extrinsic rewards, especially tangible rewards such as pay, can undermine intrinsic motivation (e.g., Deci et al., 1999). This means that organizations must carefully monitor the way they structure work, to the extent that it fosters intrinsic motivation; the way they incent work, to the extent that it fosters extrinsic motivation; and the potential for those to influence each other in unanticipated ways. 


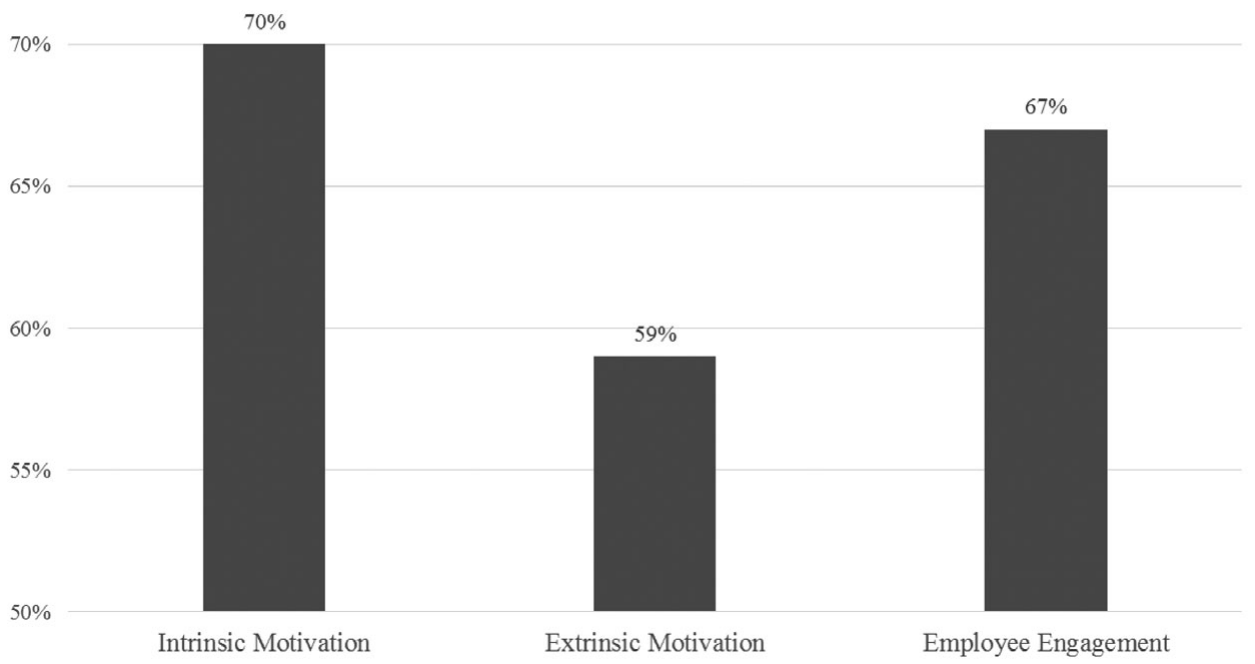

Figure 1. Korn Ferry Hay Group's Global Employee Opinion Normative Benchmarks for Intrinsic Motivation, Extrinsic Motivation, and Employee Engagement.

\section{The Motivation Gap}

The fact that both intrinsic and extrinsic motivation drive behavior would lead us to believe that they are related to one another-and, according to our research, there is a strong correlation between them. When we look at the proportion of employees who positively endorse our measures of these constructs, however, we observe a large and consistent motivation gap that signals a real opportunity for organizations to drive behavior more effectively. More specifically, we find that intrinsic motivation is consistently higher than extrinsic motivation, and the phenomenon is pervasive.

According to our normative benchmarks, $70 \%$ of employees globally report feeling intrinsically motivated, whereas only $59 \%$ of employees report feeling extrinsically motivated (see Figure 1). Importantly, we identify this motivation gap regardless of organizational geography or industry, and we observe this same pattern when we look at differences across employee demographics such as tenure, age, gender, or performance levels. This pattern is not a function of fundamental, inherent differences in intrinsic motivation levels; research has shown that neither gender nor age nor tenure is related to intrinsic motivation (Zhang, Kwan, Zhang, \& Wu, 2014).

We believe that these trends represent a pervasive and global phenomenon whereby employees are coming to work each day ready to satisfy internally focused needs and goals, but organizations are not providing the additional inducements needed to take that energy to the next level. 
Certainly, it is challenging to disentangle the extent to which employees may be naturally more intrinsically motivated versus the extent to which organizations are failing to do enough to extrinsically motivate the workforce. Supporting the former, there is evidence to suggest that there are trait-based, personality-like differences in what motivates people. For example, those with a heightened intrinsic motivational orientation may be more inclined to prefer challenging tasks, seek out learning opportunities piqued by curiosity or interest, or set goals related to competence and mastery (e.g., Amabile et al., 1994; Gottfried, 1990; Nicholls, 1984; Nicholls, Cobb, Wood, Yackel, \& Patashnick, 1990). Whether intentional or not, contemporary hiring practices may be more effective in identifying employees with a stronger intrinsic motivational orientation; that is, organizations hire people who want the challenge of the job rather than the paycheck that comes with it. This could mean that there is a systematically greater presence of intrinsic motivation in the workforce, although, to our knowledge, research has not tested this idea. At the same time, however, preference for difficult tasks and striving for competency can be linked to extrinsic motivation as well (Eccles \& Wigfield, 2002), such that both types of motivation can come preprogrammed in the workforce.

Still, we believe this gap signals that organizations rely too heavily on the motivation employees bring to work with them each day and that there is a distinct opportunity for organizations to improve their ability to motivate behavior. Like many, we calculate engagement by averaging scores from several indicators, including intrinsic and extrinsic motivation. According to our benchmarks, $67 \%$ of employees are engaged, globally. With $70 \%$ of employees feeling personally motivated to do more than is required of them, intrinsic motivation is having a positive impact on overall engagement levels. At the same time, the $59 \%$ of employees who feel that the company motivates them to do more than is required (our lowest-scoring engagement item) is pulling overall engagement scores down. In this way, extrinsic motivation is setting a limit on engagement levels.

From a more tactical perspective, our research suggests there are distinct opportunities for organizations to improve their ability to enable energized employees to perform at their best (Royal \& Agnew, 2011). For example, our research confirms that confidence in the ability to achieve career objectives is one of the most critical drivers of employee engagement, yet only $54 \%$ of employees hold positive views in this area. We also know that $30 \%$ of employees are missing the authority they need to do their jobs well, $47 \%$ struggle to receive adequate support from other teams, and $49 \%$ give organizations low marks for being effectively organized and structured. Each of these areas can be improved if organizations put the right programs and processes in place. 
Finally, from a practical perspective, organizations can do more to influence extrinsic motivation. Intrinsic motivation may lead to better performance, but it is difficult to move-many organizations struggle to strategically and systematically change sources of intrinsic motivation (i.e., curiosity and genuine interests), and job-related tasks may not always be intrinsically motivating. Instead, they can focus on external factors (e.g., tangible rewards, available supporting structures) that are easier to manipulate in order to enhance the perceived intrinsic motivation. For example, Deci, Connell, and Ryan (1989) found that organizations are more effective when they create structures that facilitate attainment of extrinsic rewards, such as job satisfaction, pay, and benefits.

\section{Signal or Noise?}

Previously, we cited evidence to suggest that extrinsic motivation is an important way to drive behavior but that intrinsic motivation is more closely associated with high performance and improved engagement. If extrinsic motivation is having less impact on the indicators organizations care about most, why focus on it at all? We also said that organizations are better equipped to address extrinsic motivation. Just because they can, does that mean they should?

We believe that the motivation gap represents a real opportunity to engage employees in a way that resonates powerfully and improves return on investment. According to one estimate, companies spend over $\$ 720$ million each year on employee engagement (Kowske, 2012), and that number is projected to rise to over $\$ 1.5$ billion (LaMotte, 2015). Investments in engagement are sound, and our data suggest that they have paid off. Engagement has slowly yet steadily risen in the past decade. If investments were having the proper return on investment, however, we should expect that extrinsic motivation would have increased more substantially over time and that it would support rather than inhibit overall engagement levels. Engagement has risen in the past decade in spite of depressed extrinsic motivation, so although the return on engagement is still positive, it is not as strong as it could be. We believe that a greater return is possible through targeted and strategic investments in extrinsic motivation, which can raise the limits that extrinsic motivation has placed on overall engagement and direct employee behavior in new ways.

\section{Closing the Gap}

Although closing the motivation gap may not be an end in itself, organizations that do more to extrinsically motivate their people will achieve a greater return on their investment and enjoy higher levels of overall engagement. Enhancing the extent to which they directly motivate behavior through 
positive work environments and valued incentives is the right start. But it is equally important for them to ensure that this motivation gap doesn't grow wider. The gap between intrinsic and extrinsic motivation creates an internal state of tension; it is uncomfortable for employees to know that the motivation they bring with them each day is not matched by the organization to which they are committed. This type of inconsistency breeds discomfort, and, as with any psychological state of tension, employees will look to resolve it by establishing consistency in their experiences. More specifically, they will attempt to close the motivation gap and create consistency across motivation sources, thereby reducing their discomfort and creating a more stable state of equilibrium (Festinger, 1957). This commonly occurs in one of three ways. First, they can seek out opportunities for the organization to meet them where they are and improve their extrinsic motivation in the form of pay raises or bonuses, enhanced benefits, improved work environments, or opportunities to assume new roles. Alternatively, their intrinsic motivation could decline, such that employees opt not to acknowledge or appreciate the extent to which their work experiences validate internal needs and values. Finally, they can choose to disengage altogether and look for opportunities at other organizations that will motivate their best performance. For example, we find that employees who are planning to stay with the organization for only 1 to 2 years have a motivation gap of 14 percentage points, 3 percentage points greater than the norm.

This psychological tension is also the reason why organizations must be careful not to overcorrect. Because internal states of tension are sensitive, we caution overreliance on extrinsic motivators and strongly advocate for the careful, strategic implementation thereof. Earlier, we indicated that extrinsic motivators in the form of tangible rewards can undermine intrinsic motivation, and one of the earliest explanations is based on the internal tension created by contradiction. Festinger (1967) argued that external rewards affect employee perceptions of why they are working and what attitudes they hold toward that work. Reasoning from his theory of cognitive dissonance (Festinger, 1957), he predicted that external rewards should decrease intrinsic motivation. If organizations want to help close the motivation gap by introducing extrinsic rewards, they must do so strategically, and at the right pace, in order to ensure that intrinsic motivation does not unintentionally unravel.

By implementing the right structures and processes at the right pace, organizations can slowly work to close the gap or, at a minimum, ensure it does not grow wider. Not only do these interventions improve extrinsic motivation directly but, by extension, those efforts can have an indirect impact on intrinsic motivation as well (Yoo et al., 2012). The key is for organizations to understand what drives intrinsic and extrinsic motivation. 
Our conceptualization of intrinsic motivation holds that it is driven by work experiences that resonate with employees in terms of their individual needs, wants, values, and abilities. Our research provides support, in that we found the primary driver of intrinsic motivation to be the presence of challenging and interesting work, followed by the absence of institutional barriers to success. In combination, this suggests that an organization's enabling structures and processes are key, job-focused elements of intrinsic motivation.

There are also environmental elements that can impact the extent to which employees feel supported at work. Our research shows that intrinsic motivation is also driven by appreciation for employee differences, opportunities to devise new ways of working, and recognition or praise from immediate managers. Together, these drivers suggest that employees who believe that work is within their control, and feel validated for the work they do, are better positioned to have a lasting impact based on their unique contributions to organizational goals.

Conversely, our conceptualization of extrinsic motivation holds that it is driven by formal inducements, or that which positions employees to receive tangible returns in the form of rewards or status. Although this is commonly achieved in the form of financial gains, it is important for organizations to consider the indirect mechanisms by which employees might achieve the same ends, such as by earning a promotion, receiving a high performance rating, having exposure to senior leaders, or leading a highly visible team or project.

Our research suggests that extrinsic motivation is driven primarily by the extent to which organizations attract high-quality employees. A strong employee value proposition signals that the organization has a strong reputation in the market and is capable of recruiting key talent. But, perhaps more importantly, it also supports the perception that employees work for a winning organization, and, by a transitive property, organizational success equates to individual success.

We also found that availability of career opportunities drives extrinsic motivation. Certainly, the opportunity to develop new knowledge, skills, and abilities has intrinsically motivating properties, particularly if the process provides access to challenging and interesting work. At the same time, however, we also believe that these opportunities open doors to new projects, experiences, and roles, whether lateral or vertical in nature, which externally validate one's abilities and create opportunities for greater status or visibility.

The results of these driver analyses provide evidence to support the conceptual underpinnings of these two types of motivation (see Table 2). Additionally, they highlight the fact that, although they motivate behavior via 
Table 2. A Summary of Key Drivers of Intrinsic and Extrinsic Motivation

\begin{tabular}{ll}
\hline \hline To support intrinsic motivation & To support extrinsic motivation \\
\hline - Create opportunities for employees do to & - Establish a strong value proposition to \\
challenging and interesting work that & attract key talent and remind employees \\
fully leverages their skills and abilities & why they work for a winning team \\
- Remove bureaucracy, poorly designed & - Help employees to connect learning and \\
processes, and other institutional & development opportunities with future \\
barriers that stand in the way & roles and career paths \\
- Empower employees to devise new ways & - Ensure that financial rewards are fair and \\
of working based on their unique & competitive without overstating the \\
differences and perspectives & importance of rewards as a motivator \\
- Encourage managers to recognize & - Publically recognize exceptional \\
employees who go above and beyond & performance \\
\hline \hline
\end{tabular}

different pathways and result in different outcomes, they are still highly related to one another and, in fact, are rather sensitive to organizational context.

For example, we found that when managers provide recognition and praise for good work, it is intrinsically motivating. Although recognition, in isolation, might connote extrinsic motivation via status and visibility, we believe there are two explanations for this finding. First, managers are proximal to work experiences and develop one-on-one relationships with employees. Praise and recognition from a close other, particularly one who understands the nature and context behind the work and appreciates its complexity, likely access and validate employees' internal need to do work that reflects their capabilities to the fullest extent. In this sense, the work is personal, and praise is as much a reflection of one's abilities as it is about one's outputs. At the same time, when employees are recognized for good work in a broader sense, without reference to praise or close others, it is extrinsically motivating. Without added context, employees are likely to interpret recognition based on the extent to which it connotes status or visibility throughout the organization and, as a result, can interpret it based on its utility. This means that recognition can be either intrinsically or extrinsically motivating depending on how it is delivered.

Organizations should focus on reducing the motivation gap in order to ensure that employees perform at optimal levels. The fact that intrinsic motivation is consistently higher than extrinsic motivation suggests that employees are coming to work each day ready to satisfy internally focused needs and goals, but organizations are not providing the additional inducements needed to take that energy to the next level. As a result, efforts directed toward improving extrinsic motivation are well placed. 
Organizations can start by improving the factors that drive extrinsic motivation, such as developing successful recruitment and onboarding strategies, promoting employee recognition programs, and encouraging innovative behavior. The benefit of this approach is the indirect impact on intrinsic motivation as well, as organizations that empower and recognize good work drive motivation via both extrinsic and intrinsic pathways. Organizations would be remiss to neglect intrinsic motivation but should acknowledge that it is harder and more time consuming to influence given that it taps into very personal aspects of an employee's work experiences. This means that organizations are likely to have the best success if they promote intrinsic motivation via two different pathways: directly via key drivers, such as having challenging and interesting work, and indirectly, via extrinsic motivation.

Finally, knowing that intrinsic and extrinsic motivation may not always align, an additional intervention might involve profiling the organization in order to understand whether key groups are experiencing significant motivation gaps and direct action plans accordingly. In particular, based on normative data, we suggest that it is possible to classify employees into three groups: (a) those who are high on both intrinsic and extrinsic motivation and, as a result, are likely to be the most engaged; (b) those who are low on both intrinsic and extrinsic motivation and, as a result, are likely to be detached from the organization; and (c) those who are high on intrinsic and low on extrinsic motivation, reflecting the general pattern of findings we observed in our normative data. This particular group is likely to experience the greatest tension and may be at risk for disengagement via reduced intrinsic motivation or possible attrition from the organization altogether.

Employee engagement is a foundational element of human capital strategies, yet we cannot understand it fully until we take an in-depth look at its component parts. In particular, intrinsic and extrinsic motivation are dynamic factors that significantly contribute to overall engagement levels but have yet to be highlighted in a systematic and strategic way. We hope this creates a new dialogue around engagement and encourages organizations to evaluate their understanding of the construct by breaking it down-and, as a result, moving it more quickly.

The Idea in Brief:

Motivation is a key aspect of employee engagement, and intrinsic (internal) motivation is consistently higher than extrinsic (external) motivation. Because extrinsic motivation sets a limit on high engagement, organizations can achieve greater returns on engagement investments 


\section{by focusing on extrinsic motivators. Strategies should include providing meaningful career development opportunities, recognizing employee ef- forts in public ways, and helping employees understand why they are part of a winning team through a strong value proposition. When extrinsic and intrinsic motivators are carefully aligned, the result will be higher en- gagement and more inspired performance.}

\section{References}

Amabile, T. M., Hill, K. G., Hennessey, B. A., \& Tighe, E. (1994). The work preference inventory: Assessing intrinsic and extrinsic motivational orientations. Journal of Personality and Social Psychology, 66, 950-967.

Baard, P. P., Deci, E. L., \& Ryan, R. M. (2004). Intrinsic need satisfaction: A motivational basis of performance and well-being in two work settings. Journal of Applied Social Psychology, 34(10), 20452068.

Baker, G. P., Jensen, M. C., \& Murphy, K. J. (1988). Compensation and incentives: Practice vs. theory. The Journal of Finance, 43(3), 593-616.

Black, A. E., \& Deci, E. L. (2000). The effects of instructors' autonomy support and students' autonomous motivation on learning organic chemistry: A self-determination theory perspective. Science Education, 84(6), 740-756.

Choi, M. (2011). Employees' attitudes toward organizational change: A literature review. Human Resource Management, 50(4), 479-500.

Deci, E. L. (1971). Effects of externally mediated rewards on intrinsic motivation. Journal of Personality and Social Psychology, 18, 105-115.

Deci, E. L. (1995). Why we do what we do: Understanding self-motivation. New York, NY: Penguin.

Deci, E. L., Connell, J. P., \& Ryan, R. M. (1989). Self-determination in a work organization. Journal of Applied Psychology, 74(4), 580.

Deci, E. L., Koestner, R., \& Ryan, R. M. (1999). A meta-analytic review of experiments examining the effects of extrinsic rewards on intrinsic motivation. Psychological Bulletin, 125(6), 627-668.

Deci, E. L., \& Ryan, R. M. (1985). Intrinsic motivation and self-determination in human behavior. New York, NY: Springer.

Eccles, J. S., \& Wigfield, A. (2002). Motivational beliefs, values, and goals. Annual Review of Psychology, 53(1), 109-132.

Festinger, L. (1957). A theory of cognitive dissonance. Redwood City, CA: Stanford University Press.

Festinger, L. (1967, March). The effect of compensation on cognitive processes. Paper presented at the McKinsey Foundation Conference on Managerial Compensation, Tarrytown, NY.

Gerhart, B., \& Rynes, S. (2003). Compensation: Theory, evidence, and strategic implications. Thousand Oaks, CA: Sage.

Grant, A. M. (2008). Does intrinsic motivation fuel the prosocial fire? Motivational synergy in predicting persistence, performance, and productivity. Journal of Applied Psychology, 93(1), 48-58.

Griffin, M. A., Parker, S. K., \& Neal, A. (2008). Is behavioral engagement a distinct and useful construct? Industrial and Organizational Psychology: Perspectives on Science and Practice, 1, 48-51.

Gottfried, A. E. (1990). Academic intrinsic motivation in young elementary school children. Journal of Educational Psychology, 82(3), 525-538.

Harter, J. K., Schmidt, F. L., \& Hayes, T. L. (2002). Business-unit-level relationship between employee satisfaction, employee engagement, and business outcomes: A meta-analysis. Journal of Applied Psychology, 87(2), 268-279.

Jenkins, D. Jr., Mitra, A., Gupta, N., \& Shaw, J. (1998). Are financial incentives related to performance? A meta-analytic review of empirical literature. Journal of Applied Psychology, 83, 777-787.

Kowske, B. (2012). Employee engagement: Market review, buyer's guide, and provider profiles. Oakland, CA: Bersin \& Associates. 
Kinnie, N., Hutchinson, S., Purcell, J., \& Swart, J. (2006). Human resource management and organizational performance. In T. Edman \& A. Wilkinson (Eds.), Contemporary human resource management: Texts and cases (pp. 26-64). London, UK: Prentice Hall.

LaMotte, S. (2015). Employee engagement depends on what happens outside of the office. Har vard Business Review. Retrieved from https://hbr.org/2015/01/employee-engagement-dependson-what-happens-outside-of-the-office

Locke, E. A., Feren, D. B., McCaleb, V. M., Shaw, K. N., \& Denny, A. T. (1980). The relative effectiveness of four methods of motivating employee performance. In K. D. Duncan, M. M. Gruneberg, \& D. Wallis (Eds.), Changes in working life (pp. 636-383). London, UK: Wiley.

Locke, E. A., Shaw, K. N., Saari, L. M., \& Latham, G. P. (1981). Goal setting and task performance: 1969-1980. Psychological Bulletin, 90(1), 125-152.

Lockwood, N. R. (2007). Leveraging employee engagement for competitive advantage: HR's strategic role. Society for Human Resource Management Research Quarterly, 52(3), 1-11.

Nicholls, J. G. (1984). Achievement motivation: Conceptions of ability, subjective experience, task choice, and performance. Psychological Review, 91(3), 328-346.

Nicholls, J. G., Cobb, P., Wood, T., Yackel, E., \& Patashnick, M. (1990). Assessing students' theories of success in mathematics: Individual and classroom differences. Journal for Research in Mathematics Education, 21(2), 109-122.

Royal, M. A., \& Agnew, T. G. (2011). The enemy of engagement: Put an end to workplace frustrationand get the most from your employees. New York, NY: AMACOM.

Ryan, R. M., \& Deci, E. L. (2000). Self-determination theory and the facilitation of intrinsic motivation, social development, and well-being. American Psychologist, 55(1), 68-78.

Ryan, R. M., \& Deci, E. L. (2008). From ego depletion to vitality: Theory and findings concerning the facilitation of energy available to the self. Social and Personality Psychology Compass, 2(2), 702-717.

Skaggs, K. J., Dickinson, A. M., \& O'Connor, K. A. (1992). The use of concurrent schedules to evaluate the effects of extrinsic rewards on intrinsic motivation: A replication. Journal of Organizational Behavior Management, 12, 45-83.

Vroom, V. R. (1964). Work and motivation. New York, NY: Wiley.

Williams, G. C., Grow, V. M., Freedman, Z. R., Ryan, R. M., \& Deci, E. L. (1996). Motivational predictors of weight loss and weight-loss maintenance. Journal of Personality and Social Psychology, 70(1), 115-126.

Yoo, S. J., Han, S. H., \& Huang, W. (2012). The roles of intrinsic motivators and extrinsic motivators in promoting e-learning in the workplace: A case from South Korea. Computers in Human Behavior, 28(3), 942-950.

Zhang, H., Kwan, H. K., Zhang, X., \& Wu, L. (2014). High core self-evaluators maintain creativity: A motivational model of abusive supervision. Journal of Management, 26, 1-22. 